\title{
The Influence of Different Arrangements of Steam Cooler on Steam Turbine Thermal Efficiency
}

\author{
Yuan-Shu ZHANG ${ }^{1, a}$ and Sha LIU ${ }^{2, b}$ \\ ${ }^{1}$ Huadian Electric Power Research Institute Co., LTE, Hangzhou 310030, Zhejiang Province, China \\ ${ }^{2}$ Jingling Institute of Technology, Nanjing 211169, Jiangsu Province, China \\ ayuanshu-zhang@chder.com, b898957024@qq.com
}

Keywords: Parallel steam cooler, Series steam cooler, Thermal efficiency.

\begin{abstract}
For a reheat-regenerative cycle steam turbine, the increased superheat of extraction steam after reheating causes the regenerative effect to weaken. Steam cooler can make rational use of the superheat of the extraction steam to improve the thermal efficiency of steam turbine. Based on the heat balance calculation of steam turbine, the mathematical models of the influence of steam cooler on steam turbine thermal efficiency was established. With the models, calculated the influence of external series steam cooler and external parallel steam cooler on thermal efficiency. The calculation result shows that the thermal efficiency of the cycle with external steam cooler is higher than the cycle with integral type, and in the case of reasonable design, the efficiency of the cycle with external parallel steam cooler is higher than the cycle with series type. The analysis provides a theoretical basis for the optimization and remolding of the regenerative system.
\end{abstract}

\section{Introduction}

For a reheat-regenerative cycle turbine, the superheat of the reheated steam is increased, so that the heat transfer temperature difference of the regenerative heater after reheating is raised, resulting in an increase in entropy increase and exergy loss, thus the regenerative effect is weakened [1]. Modern steam turbine units are equipped with steam coolers to solve this problem.

The steam cooler is a device which can reasonably utilize the superheat of extraction steam and improve the thermal efficiency. It can raise the outlet water temperature of the heater or the final feed water temperature so that to reduce the negative effect of reheat.

There are two kinds of steam cooler, integral type and external type. The integral type has the advantages of simple structure, less steel consumption and lower cost; however, it can only increase the outlet water temperature of the heater corresponding to the extraction stage $[2,3]$.

As for the external steam cooler, because of the independent shell, although which leads to more cost in steel, makes its arrangement is more flexible, and can be set at the most suitable position according to extraction steam superheat degree, thus obtaining a higher economic benefit. The external steam cooler can make more use of the superheat of the extraction steam than integral type through cross-level utilization of energy [4].

According to the different arrangements, the external steam cooler can be divided into series type and parallel type. The series type is stable but uses less superheat, and the parallel type can use more superheat, but its operation is more complex.

Based on the heat balance calculation of steam turbine cycle [5], the thermal efficiency models of the external steam cooler under different arrangement was established. Taking the $\mathrm{N} 328-16.7 / 538 / 538$ unit as an example, the influence of different arrangements of external steam cooler was analyzed. According to the analysis results, the arrangement and operation mode of the external steam cooler can be optimized to get the best unit thermal efficiency. 


\section{Thermal Efficiency Analysis Model of External Steam Cooler}

\section{External Series Steam Cooler.}

The external series steam cooler uses the superheat of the extraction steam to heat the outlet water of the last heater, improving the thermal efficiency of the unit by raising the final feedwater temperature. When arranged in series, all feedwater passes through the steam cooler, as shown in Fig. 1.

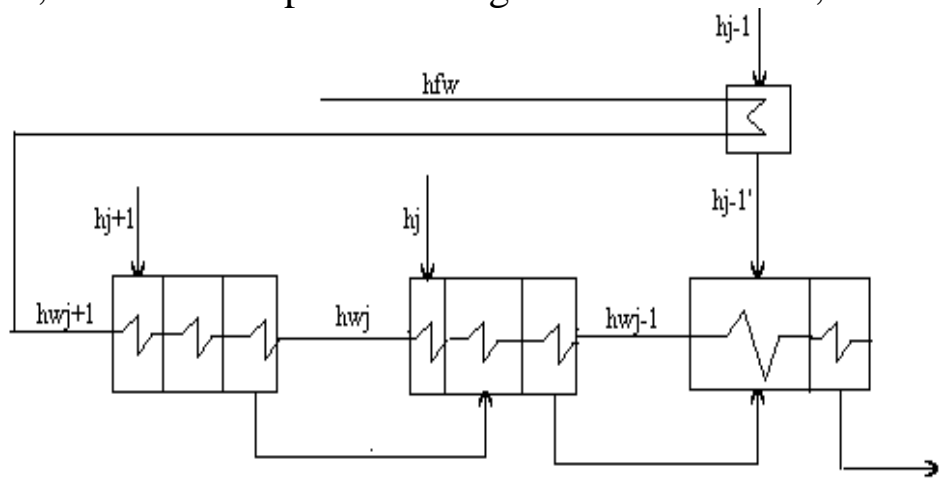

Fig. 1 External series steam cooler

The enthalpy of the final feedwater $h_{f w}$ is given by

$$
h_{f w}=h_{w j+1}+\alpha_{j-1}\left(h_{j-1}-h_{j-1}^{\prime}\right)
$$

where $h_{w j+1}$ is the enthalpy of the outlet water of the last heater, $\alpha_{j-1}$ is the ratio of mass flows between the extracting steam of $j-1$ stage and main steam, $h_{j-1}$ is the enthalpy of the extracting steam of $j-1$ stage, and $h_{j-1}$ is the exhausting steam of the steam cooler which is determined by the press of the exhausting steam $p_{j-1}$ and the temperature of the exhausting steam $t_{j-1}$. The $t_{j-1}$ is given by

$$
t_{j-1}^{\prime}=t_{w j+1}+\theta
$$

where $t_{w j+l}$ is the outlet water temperature of the last heater, and $\theta$ is the terminal temperature difference of the steam cooler. Usually, the $\theta$ is set at 10 to 25 degrees [6].

\section{External Parallel Steam Cooler.}

The system of external parallel steam cooler divides parts of the heater outlet water to the steam cooler, as shown in Fig. 2. The ratio of the dividing water flow and main steam flow is expressed in X. The determination of $\mathrm{X}$ is based on the criterion that the dividing water cannot be vaporized in the steam cooler. Because the temperature of the inlet water of the steam cooler is relatively low, the superheat of extraction steam can be fully utilized. This arrangement realizes the cascade utilization of energy, so that to obtain a better thermal efficiency.

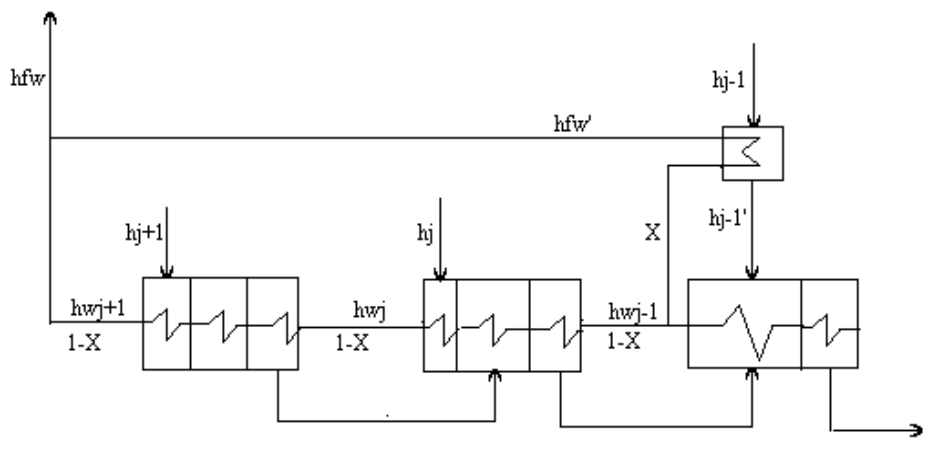

Fig. 2 External parallel steam cooler

The enthalpy of the final feedwater $h_{f w}$ is given by

$$
h_{f w}=h_{w j+1}+\alpha_{j-1}\left(h_{j-1}-h_{j-1}^{\prime}\right)-X\left(h_{w j+1}-h_{w j-1}\right)
$$


Different from the series arrangement, the temperature of the exhaust steam of the parallel steam cooler is given by

$$
t_{j-1}^{\prime}=t_{s j-1}+\psi
$$

where $t_{s j-1}$ is the saturation temperature corresponding to the press of the extraction steam, and $\psi$ is the superheat degree of the exhaust steam of the steam cooler.

\section{Example Calculation}

Taking N328-16.7/538/538 unit as an example (Fig. 3), the influence of different arrangements of steam coolers on thermal efficiency is analyzed as below. There are eight stages of feedwater heating, including three HP heaters, four LP heaters, and a deaerator. Generator efficiency $\eta_{e}=0.987$, mechanical efficiency $\eta_{m}=0.99$, extraction line pressure drops $\Delta p=0.08$, and the heat losses of the unit is not considered in the calculation.

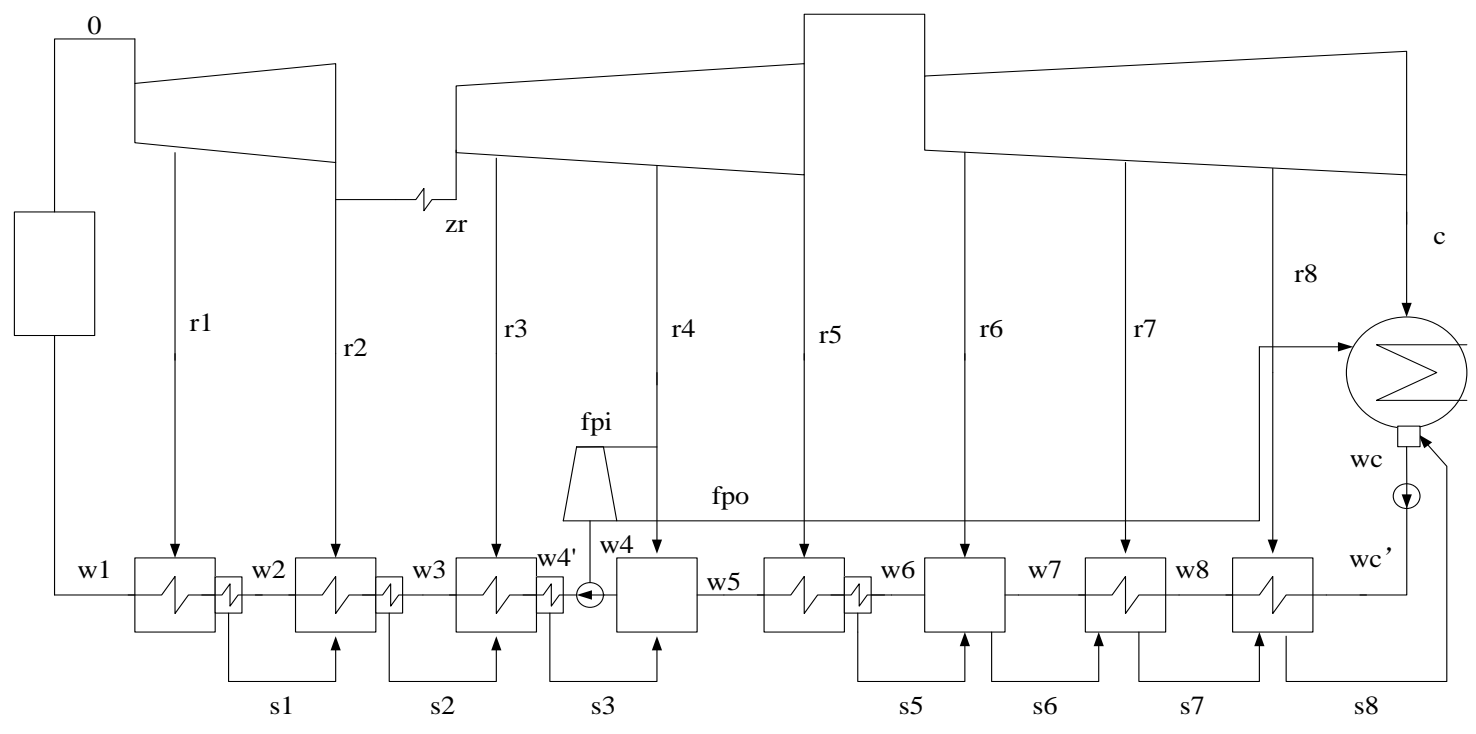

Fig. 3 N328-16.7/538/538 Steam turbine cycle

\section{The Thermal Efficiency of the Original Cycle.}

The thermal economic indicators are shown in Table 1, and the profit analysis of external steam coolers is based on the thermal efficiency of the original cycle.

Table 1 Economic indicators of the original cycle

\begin{tabular}{cccc}
\hline Indicators & Symbol & Units & Values \\
\hline Net heat to the cycle & $q_{0}$ & $\mathrm{~kJ} / \mathrm{kg}$ & 2551.28 \\
Discharge heat of the cycle & $q_{c}$ & $\mathrm{~kJ} / \mathrm{kg}$ & 1388.15 \\
Shaft power of the cycle & $w_{i}$ & $\mathrm{~kJ} / \mathrm{kg}$ & 1163.13 \\
Cycle efficiency & $\eta_{i}$ & $\%$ & 45.59 \\
Heat rate & $\mathrm{HR}$ & $\mathrm{kJ} / \mathrm{kg}$ & 8097.69 \\
\hline
\end{tabular}

\section{Profit Analysis of the External Series Steam Cooler.}

The third extraction stage of the unit is the first stage after reheating; the superheat of the third extraction steam is larger than any other stage. Therefore, profit of setting the steam cooler at the third extraction stage will be analyzed in the following article. For external series steam cooler, the temperature of the exhaust steam is calculated by Eq. 2, set the terminal temperature difference of the steam cooler $\theta$ as 25 degrees and the press loss at steam cooler as $2 \%$. The thermal economic indicators for the cycle with external series steam cooler are shown in Table 2. 
Table 2 Economic indicators of the cycle with external series steam cooler

\begin{tabular}{cccc}
\hline Indicators & Symbol & Units & Values \\
\hline Net heat to the cycle & $q_{0}$ & $\mathrm{~kJ} / \mathrm{kg}$ & 2533.78 \\
Discharge heat of the cycle & $q_{c}$ & $\mathrm{~kJ} / \mathrm{kg}$ & 1376.1 \\
Shaft power of the cycle & $w_{i}$ & $\mathrm{~kJ} / \mathrm{kg}$ & 1157.68 \\
Cycle efficiency & $\eta_{i}$ & $\%$ & 45.69 \\
Heat rate & $\mathrm{HR}$ & $\mathrm{kJ} / \mathrm{kg}$ & 8079.97 \\
\hline
\end{tabular}

\section{Profit Analysis of the External Parallel Steam Cooler.}

For external parallel steam cooler, the temperature of the exhaust steam is calculated by Eq. 4, set the superheat degree $\psi$ as 25 degrees and the press loss at steam cooler as $2 \%$. The thermal economic indicators for the cycle with external parallel steam cooler are shown in Table 3.

Table 3 Economic indicators of the cycle with external parallel steam cooler

\begin{tabular}{cccc}
\hline Indicators & Symbol & Units & Values \\
\hline Net heat to the cycle & $q_{0}$ & $\mathrm{~kJ} / \mathrm{kg}$ & 2539.13 \\
Discharge heat of the cycle & $q_{c}$ & $\mathrm{~kJ} / \mathrm{kg}$ & 1374.43 \\
Shaft power of the cycle & $w_{i}$ & $\mathrm{~kJ} / \mathrm{kg}$ & 1164.7 \\
Cycle efficiency & $\eta_{i}$ & $\%$ & 45.87 \\
Heat rate & $\mathrm{HR}$ & $\mathrm{kJ} / \mathrm{kg}$ & 8048.26 \\
\hline
\end{tabular}

\section{Analysis.}

As shown in Fig. 4, the cycle efficiency of the original cycle with integral steam cooler is $45.59 \%$, the cycle efficiency of the cycle with external series steam cooler is 45.69 , and the cycle efficiency of the cycle with external parallel steam cooler is $45.87 \%$. Compared with external series steam cooler or integral steam cooler, the cycle efficiency of the steam turbine unit has been significantly improved by using external parallel steam cooler.

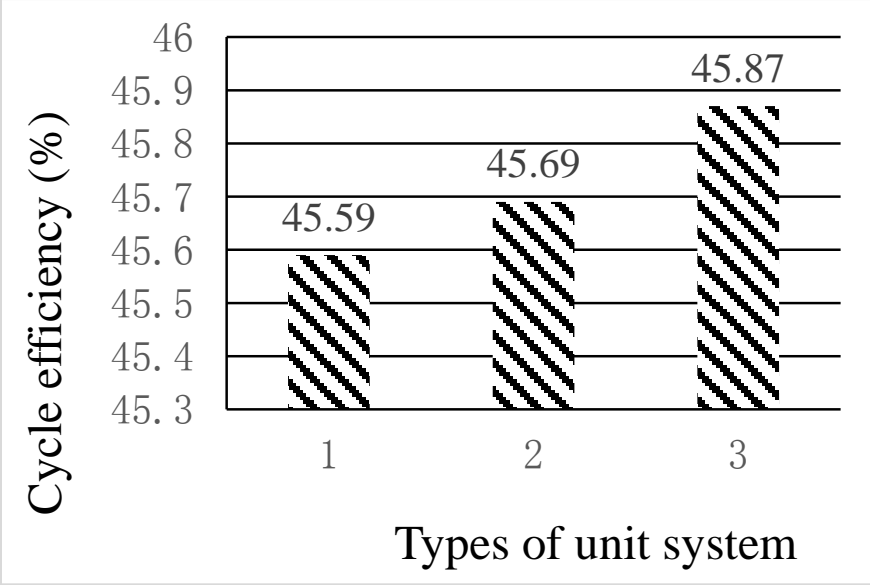

Fig. 4 Cycle efficiency of different unit systems

\section{Conclusions}

The external steam cooler can realize the cascade utilization of energy, which can not only reduce the terminal temperature difference of the heater, but also raise the temperature of the final feedwater, thus the utilization of the superheat of the extraction steam is sufficient, while the integral steam cooler can just reduce the outlet temperature difference of the current heater, so the cycle efficiency of the external steam cooler is higher than integral type.

Under the condition of the same overheat; the cycle efficiency of the external parallel steam cooler is higher than the external series steam cooler. The rational selection of the arrangement of the steam cooler is of great significance to the energy saving optimization for the thermal steam turbine unit. 


\section{References}

[1] Guo-Dong Lu, Chun-Fa Zhang, Yan Sun, Research on the Partial Load Property of Standard Number of the Temperature Difference of Heater with Steam-cooling Segment, J. Turbine Technology 02(2008) 126-130.

[2] Xiu-Yun Li, Jun-Jie Yan, Wan-Chao Lin, Research on Variable Load Operation Performance of Regenerative Heater with Superheated Steam Cooler, J. Electric Power 01(2001) 24-27.

[3] Xiu-Yun Li, Jun-Jie Yan, Chun-Yu Zhang, Economic Diagnosis Method of Thermal System with Outer Steam Cooler, J. Proceedings of the CSEE 01(2001) 35-39.

[4] Frangopoulos C A, Caralis Y C, A Method for Taking into Account Environmental Impacts in the Economic Evaluation of Energy Systems, J. Energy Conversion and Management. 1997, 38(15-17): 1751-1763.

[5] Hua B, Chen Q L, Wang P, A New Exergy Economic Approach for Analysis and Optimization of Energy Systems, J. Energy. 1997, 22(11): 1071-1078.

[6] Zheng-Yong Wu, Pei-Hong Wang, General Calculation Model on the Influence of Terminal Temperature Difference on Heat Economy of Unit, J. Turbine Technology 03(2008) 226-229. 